\title{
Correction to: Mechanisms and microbial structure of partial denitrification with high nitrite accumulation
}

\author{
Rui $\mathrm{Du}^{1} \cdot$ Yongzhen Peng ${ }^{1} \cdot$ Shenbin $\mathrm{Cao}^{2} \cdot$ Baikun $\mathrm{Li}^{3} \cdot$ Shuying Wang ${ }^{1} \cdot \mathrm{Meng} \mathrm{Niu}^{1}$
}

Published online: 19 February 2020

(C) Springer-Verlag GmbH Germany, part of Springer Nature 2020

\section{Correction to: Appl Microbiol Biotechnol (2016) 100:2011-2021} https://doi.org/10.1007/s00253-015-7052-9

In the published version of the above article, the affiliation of one of the co-authors (Baikun Li) is incorrect. The correct and final version is shown below:

Baikun Li, Department of Civil and Environmental Engineering, University of Connecticut, Storrs, CT 06269, United States.

The authors would like to apologise for any inconvenience caused.

Publisher's note Springer Nature remains neutral with regard to jurisdictional claims in published maps and institutional affiliations.

The online version of the original article can be found at https://doi.org/ $10.1007 / \mathrm{s} 00253-015-7052-9$

\section{Yongzhen Peng}

pyz@bjut.edu.cn

1 Engineering Research Center of Beijing, Key Laboratory of Beijing for Water Quality Science and Water Environment Recovery Engineering, Beijing University of Technology, Pingleyuan 100, Chaoyang District, Beijing 100124, People's Republic of China

2 State Key Laboratory of Urban Water Resource and Environment, Harbin Institute of Technology, Harbin 150090, China

3 Department of Civil and Environmental Engineering, University of Connecticut, Storrs, CT 06269, USA 